\title{
El Museu de la Seda de València: accions educatives
}

\section{Joaquín Aparici Martí *}

\section{Resum}

El Museu de la Seda de València presenta una sèrie de punts forts per desenvolupar accions educatives i facilitar la seua posterior projecció digital en relació al patrimoni històric (el propi edifici, les exposicions permanents i les itinerants o l'arxiu gremial). Proposem l'anàlisi de les seues possibilitats didàctiques i els materials adients; la identificació de l'ús real que se'n deriva (mitjançant enquestes i xarxes socials) i així observar la seua capacitat empàtica amb el destinatari per tal d'adequar, de forma progressiva i en cas necessari, l'oferta didàctica i cultural.

\section{Paraules clau}

Patrimoni, educació, didàctica, museu, seda.

Recepció original: 12 de novembre de 2019

Acceptació: 06 de març de 2020

Publicació: 30 de juny de 2020

\section{Introducció}

Sobre l'ús didàctic dels museus se n'ha escrit molt. El simple contenidor i conservador d'elements materials del passat, des dels períodes més antics fins a l'actualitat, ha donat pas a una visió del museu que interactua amb el destinatari i el destinatari interactua amb el museu, de forma més oberta i dialogant. Els museus collleccionen i conten històries sobre vides que es posen en contacte amb les històries i les vides de les persones que els visiten. Els confronten amb allò que els és familiar, però també amb allò que els és nou, generant debat i diàleg, i qüestionen al temps que són qüestionats. Els museus permeten desenvolupar espais de convivència, intercanvi, connexió, creació, etc... Amb aquesta perspectiva els museus són llocs que generen cultura des d'un vessant didàctic (González, 2008). Però l'horitzó del destinatari és ampli i per a això els museus tracten d'ajustarse als diferents nivells de referència patrimonial, històrica i didàctica, vinculant-se precisament a les necessitats de cada un d'aquests possibles destinataris (des de propostes per a educació infantil, primària o secundària, fins a especialistes en arqueologia, història o art, passant pel destinatari simplement curiós o el grup familiar que aprofita una estada per «visitar» un museu). L'exposició de materials, la col·lecció d'aquests i fins i tot la recreació de processos pot resultar magnífica. Tanmateix en ocasions no s'aconsegueix generar l'empatia necessària amb el destinatari per quant allò presentat no s'ajusta a les necessitats d'aquest. Recordem que els museus ja no són elements estàtics de conservació sinó que exerceixen una funció d'investigadors, divulgadors i també educadors (Asensio i Pol, 2003; Fernández, 2003; Álvarez i García, 2011). S'aconsegueix així que el museu siga element integrador del patrimoni històric creant un espai de reflexió, exploració, crítica i contrast, evitant la contemplació passiva i plantejant activitats que afavoreixen el desenvolupament de la curiositat, el pensament i la participació activa.

$\left(^{*}\right)$ Professor ajudant doctor, àrea de didàctica de les ciències socials (didàctica de la història). Departament de Pedagogia, Didàctica de les Ciències Socials, la Llengua i la Literatura. Universitat Jaume I, Castelló. Adreça electrònica: japarici@uji.es 
Però, com dic, el destinatari és variat. En aquest sentit, cal tenir present que és l'escola qui proporciona bona part dels destinataris dels museus (Serrat, 2008). Però cal preguntar-se quin tipus d'aprenentatge es promou en aquestes visites escolars, entenent-les dins de l'àmbit formal. Activitats complementàries que no van més enllà d'una eixida extraescolar? Tot i això, la simple eixida al museu ja suposa una cosa tan bàsica com donar a conèixer els elements patrimonials allí existents i fins i tot la possibilitat de sensibilitzar sobre la conservació i el respecte de l'herència cultural. Sí, però els grups escolars són variats, diferents, etc... i és impossible que el museu s'adapte a tots i cada un d'aquells. Per això es dissenyen activitats estandarditzades en funció dels propis estàndars establerts per la societat (com l'etapa educativa, el motiu de la visita o l'edat) (Suárez et alii, 2014). Però una altra cosa és poder esbrinar l'ús real que els centres escolars fan dels materials didàctics oferits pels museus, i si aquests materials cobreixen les necessitats dels destinataris. Tractar de veure la necessària col-laboració entre ambdues entitats culturals, valorar la relació entre oferta-demanda i valorar l'aprofitament dels recursos i materials didàctics és un dels elements claus a hores d'ara (Escribano et alii, 2019).

Així doncs podem tractar d'aprofundir i aprofitar tot el potencial que els museus poden oferir-nos. Amb investigacions avaluatives s'ha pogut percebre els diferents perfils del conjunt de destinataris i l'impacte que aquell patrimoni mostrat ha tingut sobre cada un d'ells, donant pautes als museus per poder adaptar les seues estructures (de tot tipus -didàctiques, expositives, etc...) a les possibles necessitats d'aquests destinataris tan variats. Per exemple podem trobar propostes des dels propis museus per organitzar amb certa periodicitat cursos de formació per als i les docents, amb l'objectiu de proporcionarlos eines de treball i pautes metodològiques sobre com activar els processos de reflexió $i$ crítica sobre allò contingut al museu, amb la possibilitat d'elaboració de projectes educatius transversals que puguen dur-se a terme a l'aula escolar (González, 2008). El paper dels i les docents serà fonamental doncs serà als centres educatius on florirà l'activitat educativa que després es podrà reforçar al propi museu. D'aquesta manera s'evitaria certa situació detectada per alguns autors que observaven com el o la docent quedava en un segon plànol, certament minoritzat, davant l'explicació del monitor d'un museu, en aquest cas concret en museus d'art (Huerta, 2011).

També és necessari plantejar la possibilitat d'establir alguna mena de proposta que abaste al públic familiar amb activitats d'aprenentatge informal, basades en elements manipulables i sensorials, pensades especialment per a fomentar la curiositat i desenvolupar els sentits. II.luminació, olors, sons i sorolls poden ajudar a percebre emocions empàtiques respecte a l'exposició. I tampoc podem oblidar-nos de l'anomenat turisme cultural, que pot tenir un interés diferent al familiar i escolar però que té un protagonisme destacat com a font financera. Apropar el discurs museístic i didàctic a aquest tipus de destinatari no significa necessàriament desantendre'n la funció educativa. Caldria doncs plantejar-se diversos graus d'interactivitat amb aquests destinataris (tipus de panells explicatius i models d'escriptura, pantalles tàctils però a diverses alçàries segons les edats dels destinataris, peces manipulables a l'abast de tots, elements lúdics, etc.). També cal atendre a l'ergonomia dins del museu doncs forma part de l'estratègia de comunicació. Afavorir àrees de descans, de circulació, evitar postures forçades situant els recursos comunicatius a una alçada i distància adequades a la mirada; les condicions d'il.luminació i so; la gradació climàtica a l'interior de l'espai museístic, etc... elements que permetran als destinataris evitar certa fatiga i aconseguir que mantinguen la seua atenció (Besolí, 200102). Cal tenir en compte que tot això depèn del propi projecte didàctic que genera el 
museu (Calaf, 2009). Per exemple, el factor didàctic es perd en ocasions si als panells no hi ha una correcta explicació en diversos idiomes; o si es sobrecarrega excessivament una sala amb peces o estímuls; o si l'espai s'ompli amb nombrosos panells explicatius quan la dinàmica general dels destinataris sol ser tot el contrari, és a dir, llegir el menys possible. Fins i tot uns materials didàctics excel-lents poden passar desapercebuts si no s'ha atès correctament a la seua projecció i difusió entre els destinataris. Però també és cert que una part important de l'èxit radica en l'actitud prèvia d'aquest mateix destinatari, en la forma en què aborda la visita i interactua amb el museu (a nivell individual o en el cas d'un grup d'alumnes, o també d'acord amb el context escolar general i existent en cada moment).

\section{Singularitat del tema}

Segons la LOMCE, entre els objectius generals en educació primària sorgeix la necessitat de conèixer, comprendre i respectar les diferents cultures, essent l'àrea de Ciències Socials la que fonamentalment tracta del coneixement de les formes de vida en el passat així com la importància d'aquest passat en la formació del nostre present i en la seua projecció cap al futur, incidint en l'estudi i conservació de les restes històriques (patrimoni cultural) per a poder desenvolupar eixos coneixements (Llei Orgànica per a la Millora de la Qualitat Educativa de 9 de desembre de 2013, publicada al Boletín Oficial del Estado de 10 de desembre de 2013). Ací s'entronca la legislació amb la funcionalitat didàctica dels museus. Tanmateix l'estudi de cas que ara proposem, el Museu de la Seda de València, ha tingut una atzarosa trajectòria.

Així el 22 de maig de 1981 s'atorgà el títol de Monument Històric-Artístic a la casahort del Col-legi de l'Art Major de la Seda de València. Al decret s'explicava com aquell encara conservava algunes parts antigues, tant de l'edifici medieval com de la posterior rehabilitació realitzada durant el segle XVIII. La llei 16/1985 de 25 de juny del Patrimoni Històric Espanyol ordenava a totes les administracions públiques que facilitaren els recursos i els mitjans necessaris per protegir, conservar i donar a conèixer convenientment qualsevol edifici que hagués estat declarat Monument Històric-Artístic. A més a més, per resolució del 9 de març de 1995 de la Direcció General de Patrimoni Artístic de la Generalitat Valenciana, els béns mobles que conservava el Col-legi reberen el reconeixement de Col-lecció Museogràfica Permanent, béns sobre els quals a partir d'eixe moment es deuria garantir la visita pública en horari regular, l'accés d'investigadors als seus fons i unes determinades condicions de conservació i custòdia. Amb tot, a pesar de tota aquesta normativa reguladora, no fou fins 2014 quan una entitat privada, la Fundació Hortènsia Herrero, la que assumí el mecenatge de la rehabilitació de l'edifici, que obrí les seues portes al públic el 2016 sota la denominació de Museu de la Seda de València (Navarro, 2018).

Diversos són els factors o punts forts que procuren a aquest museu un reconeixement a la seua tasca, especialment manifestat per una abundant i dilatada presència de visitants, de forma diària, a pesar d'obrir les seues portes al públic fa pocs anys com ja hem mencionat. El museu està situat en el casc històric de València, estratègicament ubicat per atendre tant al destinatari local com a qualsevol visitant que arribe a la ciutat. Ofereix un discurs museogràfic coherent que combina les nombroses peces conservades i exhibides, amb les particularitats del propi edifici (arquitectura i art), la recreació de processos tècnics, la inclusió de mitjans informàtics i audiovisuals adaptats a les noves tecnologies 
del saber, i la projecció investigadora que sorgeix no sols dels materials exposats sinó també de l'arxiu històric existent, i que té un abast internacional. Podem pensar que per la seua natura, el museu desenvolupa una tasca educativa en l'àmbit del context informal, però no hem d'oblidar també el context de l'educació formal.

En aquest sentit, el Museu de la Seda de València gaudeix d'una singularitat pròpia que li confereix amples capacitats didàctiques. La ubicació física del museu es correspon amb el carrer Hospital, número 7 (46001, València). Consta d'una planta baixa on està la sala d'exposició permanent, la sala dels telers, la tenda i el pati obert amb la zona de cafè i restaurant. A l'entresòl es situen les oficines administratives, la sala de reunions de la fundació, la biblioteca i l'arxiu documental. En la primera planta es localitzen la capella, la coneguda com Sala Pometa, la Sala de la Fama, la Sala de les Arts Menors i també els banys. Tot i que l'edifici, antic, presenta escales internes (algunes d'elles de gran importància històrica i arquitectònica), l'edifici és accessible per a les persones amb movilitat reduïda gràcies a l'existència d'un ascensor que connecta totes les plantes. El museu ofereix també audioguia en castellà, valencià, anglès, italià i francès.

Com dic, l'edifici és ja en sí mateix un important valor intrínsec del propi museu. Es tracta d'un edifici històric l'origen del qual es remunta a finals del segle XV quan el gremi de velluters el comprà com a seu de la seua corporació d'ofici. Tot i que al llarg dels segles ha patit determinades remodelacions, encara conserva elements del període gòtic i una distribució interna en sales típica d'altres temps passats. Eixa estructura interna, juntament amb els seus components arquitectònics i també a la decoració original del període històric que l'acompanya, són elements que ja ens mostren directament un passeig per la història de l'art. Així destaca la decoració ceràmica del paviment en la Sala Pometa; la decoració ceràmica del paviment de la Sala de la Fama (visible però protegida de les trepitjades dels visitants, per la qual cosa dit paviment està projectat a tamany real en una imatge sobre la paret del fons de la sala). En aquesta mateixa sala destaquen també les pintures del sostre relatives a sant Jerònim, pintures atribuïdes a Vergara; o fins i tot les ceràmiques i pintures al-legòriques que trobem en l'escalinata d'accés a la primera planta (Liceras, 2018).

Altre punt fort del museu és el seu arxiu històric i biblioteca. Més enllà de l'exposició de peces històriques relatives al món de la seda, el museu ofereix al destinatari una sala de visualització de documents històrics (alguns originals i altres facsímils) que són una mostra del potencial informatiu que existeix en el seu fons documental. Una pantalla de televisió ens mostra, mitjançant un breu video explicatiu, la història i configuració de l'arxiu i del seu important tresor patrimonial. En aquesta mateixa sala s'ha incorporat una gran pantalla tàctil en la qual el destinatari pot accedir a una selecció de documents digitalitzats i accessibles que permeten el visionat, l'ampliació d'aquests segons les necessitats del lector, etc. i que generalment capten l'atenció dels visitants més menuts per la seua capacitat d'interactuació. Periòdicament el museu integra en aquesta pantalla nous documents digitalitzats, de manera que de forma progressiva el conjunt accessible es fa més voluminós. Al costat d'aquesta sala, i amb accés per a estudiosos i investigadors, trobem la biblioteca, amb més d'un miler de volums que fan menció no sols a estudis sobre la seda, la indumentària o la manufactura tèxtil, sinó també a altres elements propis de la vida i la societat valenciana, europea i fins i tot asiàtica, que engloben una ampla cronologia. Finalment i ja per a un destinatari especialitzat, en una cambra cuirassada que 
manté òptimes condicions mediambientals per a la correcta conservació de la documentació (humitat, il.luminació i temperatura), els documents històrics es situen en estants i caixons, conservant l'arxiu l'activitat escrita generada per l'actuació del propi ofici i gremi de velluters al llarg dels seus cinc segles d'història, essent considerat com l'arxiu gremial més complet i ampli del món. Els investigadors, previ concert de cita, poden accedir a eixa documentació per a desenvolupar els seus projectes i estudis. D'aquest arxiu han sorgit importants investigacions, tesis de llicenciatura i tesis doctorals, que han permès conèixer àmpliament no sols la història de l'ofici i gremi de velluters sinó també la vida dels membres que en formaven part, donant valor humà a les investigacions sobre la producció o la tècnica (és a dir, aproximant-se al treballador més enllà del treball, a la vida diària després de les hores de producció, a l'èxit o fracàs de les iniciatives de vida desenvolupades pels individus, etc.). La història de la producció de seda s'ha vist així complementada amb la història de les persones que en formaven part de l'ofici. Destaquen en aquest aspecte els nombrosos estudis i investigacions del professor German Navarro, especialista de reconegut prestigi a nivell internacional, qui ha abordat el tema tant des de la perspectiva de la pròpia producció sedera i la seua evolució històrica (Navarro, 1999) fins als seus aspectes didàctics i museístics (Navarro, 2013).

Pel que fa a les exposicions del museu, aquestes es mostren en diverses sales de l'edifici. La concepció de l'espai museístic permet treballar elements necessaris a nivell didàctic relacionats amb la història i les ciències socials com són l'espai geogràfic i paisatgístic, el temps històric (i els conceptes associats) i l'empatia (relacionada al seu voltant amb el respecte per l'herència cultural rebuda). Per accedir a les sales, i atenent al fet que el propi edifici és un conjunt històric com ja s'ha mencionat, s'ofereixen al destinatari uns mocassins de tela per cobrir el calçat amb la finalitat de no fer malbé amb el continu pas de visitants els taulellets del paviment i les escales (es connecta així al destinatari amb la necessitat de conservació del patrimoni històric).

En una de les sales (planta baixa) localitzem una exposició completa i permanent sobre la pròpia història de la seda, amb indumentària, estris i ferramentes, tipus de materials i tècniques que uneixen geogràficament diversos territoris. En aquesta sala s'articula la trobada de diferents espais del món mitjançant mapes que, des d'Àsia fins a Europa, van mostrant els itineraris geogràfics vinculats a la ruta de la seda. El recorregut fa menció als principals indrets implicats i finalitza amb un plànol antic de la ciutat de València en el qual es pot ubicar el barri de velluters, centre neuràlgic de producció sedera peninsular a finals de l'Edat Mitjana. D'aquesta manera s'acompleix amb un referent didàctic imprescindible com és la situació del fet històric en un espai determinat, el qual va evolucionant tot seguint el recorregut dels mapes.

Paral.lelament, i de forma necessària, es dona a conèixer al seu torn la complexitat del temps històric amb conceptes que conformen la temporalitat, expressada en l'exposició mitjançant relacions de passat, present i futur, atenent al canvi, la causalitat, l'evolució o el progrés. Aquest segon element imprescindible per a la comprensió didàctica de la història està adequat a la possible duració de la visita. Eixa connexió temporal la trobem a través d'elements situats en un mur cronològic que inclou dates, panells i objectes, i on destaca per exemple la recreació escenogràfica dels «canyissos dels sirgans», imatge que promou l'empatia amb bona part dels destinataris els qui, amb quasi total seguretat, han tingut en algun moment de la seua infantessa la típica caixa de sabates amb fulles de morera i cucs, que després es transformen en capolls de seda. L'empatia indubtablement 
contribueix a una millor comprensió del passat. També en aquesta sala podem veure un vídeo explicatiu sobre la producció de seda (vídeo d'inicis del segle xx però que mostra una tècnica que s'havia mantingut de forma immemorial des de l'Edat Mitjana). En aquest sentit, la visualització es converteix en un element important ja que les imatges en moviment faciliten la narració del procés alhora que el fan més intel-ligible (Besolí, 2001-2002). En aquesta mateixa sala hi trobem diversos vestits de seda de llauradors valencians datats al segle XIX (cedits temporalment per particulars) que recreen en la ment dels destinataris la unió del passat amb el present, vinculada en aquest cas als actuals vestits de les falleres.

Seguint la dinàmica de connexió temporal, a la Sala Pometa (primera planta) podem continuar treballant la relació passat, present i futur. Allí es pot observar alguna de les exposicions itinerants que connecta directament amb el món actual de la moda. En aquest sentit el museu promou exposicions que durant un lapse temporal prèviament acordat amb la persona o institució que cedeix els materials, mostra aspectes concernents tant al món de la seda com al de la indumentària o moda en general (des d'elements tèxtils, a maquetes, nines i maniquís, arribant a revistes de moda antigues i actuals), amb la qual cosa la capacitat didàctica de la mostra augmenta i s'acosta a la realitat viscuda pels destinataris.

Una altra sala (planta baixa), ubicada estratègicament al final de la visita, sorprèn als destinataris. Allí és on s'exposen els diversos torns i telers per a la producció de seda. En aquesta sala es procedia a la recreació en directe del procés tècnic de fabricació del fil i del drap de seda, procés el funcionament del qual era explicat al visitant personalment, i fins fa molt poc de temps, per Vicent Enguídanos, un dels últims artífexs d'aquest art, el que conferia un caràcter didàctic inusitat al propi museu davant la perspectiva de poder preguntar en persona qualsevol dubte. Açò incidia molt positivament en la visita doncs la participació del destinatari era fluïda, amb aportacions i qüestions que permetien reconduir les explicacions cap a nous temes d'interés. Malauradament, en aquests moments i per la seua avançada edat que li impedia acudir diàriament al museu, l'explicació del saber pràctic ha estat substituïda per un vídeo didàctic.

Finalment una de les particularitats de qualsevol museu és la de mostrar els objectes que formen part del patrimoni cultural del passat, i per tant, de mostrar-nos els vectors espacials, temporals i empàtics que ja he mencionat. Cal tenir en compte que cada un d'aquests objectes, útils, fragments, etc... és al cap i a la fi una part de la història, i per tant és una font per treballar, analitzar i descobrir. Una adequada selecció d'aquests objectes pot afavorir l'acció educativa amb l'adquisició per part del destinatari de nocions com interrogació, hipòtesi, discriminació, anàlisi, síntesi, etc... Però també s'atén al turista cultural, amb peces i útils perfectament identificats i contextualitzats amb panells explicatius en diversos idiomes, tot i que de vegades els textos poden ser excessivament tècnics i no afavorir la seua lectura.

Els punts forts del museu, i la seua pròpia capacitat didàctica, fan que aquest estiga sempre atent a qualsevol reunió científica o investigació relacionada amb el tema. De fet, en aquests moments, la reunió científica que es celebrarà el proper maig del 2021 a Prato (Itàlia) i que versarà sobre la moda europea entre els segles XIII i XVIII, apareix publicitada amb grans cartells en l'entrada del museu. I precisament els colors de la seda en el gust i moda de finals de l'Edat Mitjana i inicis del segle XVI serà una de les aportacions que presentarem en aquella reunió de Prato, com veurem més endavant. 


\section{Metodologia}

La idea inicial és dur a terme un projecte d'investigació avaluativa per a mesurar les accions, els mitjans i els recursos que el museu fica a l'abast dels destinataris. A banda de les exposicions que solen ser el punt de referència del museu, cal observar les propostes didàctiques que s'elaboren per generar noves expectatives i cobrir les necessitats dels destinataris, amb l'objectiu d'atraure al major nombre possible de persones tenint en compte que, al cap i a la fi, es tracta d'una oferta didàctica i cultural que entra en competència directa amb les d'altres institucions museístiques i culturals. Ara bé, tot i que l'element quantitatiu, si és elevat (en termes de consum de l'oferta, és a dir nombre de destinataris que visiten el museu) implica intrínsecament un reconeixement al treball desenvolupat, no s'ha d'oblidar ni perdre de vista l'aprofitament didàctic que el museu ens pot oferir. En eixe sentit, cal tenir en compte tres visions respecte les possibilitats didàctiques dels museus (Serrat, 2008) com són: la consideració que des del propi museu es té en relació a la seua pròpia funció cultural i didàctica, i especialment als objectius que s'atribueixen als materials i activitats ofertats com a recursos, la seua implementació i l'ús final que se'n deriva; també la visió dels docents i de l'alumnat sobre eixa mateixa oferta didàctica del museu, amb les idees prèvies i preconcebudes, els continguts curriculars que es vol treballar, el temps disponible, etc... a l'igual que la visió del destinatari familiar o del turista cultural; i darrerament la influència que des dels organismes de l'administració educativa (estat, conselleria, etc...) ha impregnat el disseny curricular de l'educació formal que òbviament s'ha transferit, sinó tota almenys una part, als materials i activitats oferts pels museus i que poden facilitar la relació i col·laboració entre ambdues entitats educatives.

Així la idea és esbossar un projecte de futur que du per títol provisional «L'avaluació de l'acció educativa museística. Estudi de cas del Museu de la Seda de València». Aquest projecte està inicialment sota la supervisió i direcció del professor German Navarro Espinach, catedràtic d'Història Medieval de la Universitat de Saragossa qui és al seu torn coordinador del comitè científic del susdit museu. El projecte permetrà conjugar elements clau del procés d'ensenyament-aprenentatge en l'àmbit museístic com són la història, la didàctica i el patrimoni.

La metodologia de treball-investigació serà fonamentalment qualitativa mitjançant la realització d'entrevistes a persones implicades en les activitats didàctiques del museu, en línia amb les metodologies vinculades al projecte MINECO Educomunicación Web 2.0 del Patrimoni (Edu2016-78163-R) que dirigeix la professora Pilar Rivero, titular de didàctica de les Ciències Socials en la Universitat de Saragossa. En aquest sentit, la nostra idea és avaluar els tallers educatius i la comunicació en xarxes socials del Museu de la Seda de València des de la seua inauguració el 2016, utilitzant per a això una determinada ferramenta d'anàlisi qualitativa (Suárez et alii, 2013), eina que altres autors han seguit en els últims anys per a desenvolupar investigacions similars a la que ara proposem amb estudis de cas específics com el Museo Afro Brasil de São Paulo (Aso et alii, 2016); o l'anàlisi de l'actuació educativa del Museo Arqueológico de Calatayud (Rivero et alii, 2018).

L'avaluació podrà mostrar indicis de l'abast que els recursos didàctics oferts pel museu tenen sobre els diferents perfils dels destinataris, però també ens informarà de les seues necessitats, amb la finalitat d'iniciar un procés d'adaptació a aquestes i de millora dels processos de comunicació i ensenyament-aprenentatge, fent possible que l'apropa- 
ment al patrimoni sia més intel.ligible i atractiu a la vegada que rigorós i precís. Com indica R. Calaf (2009, p. 244) I'anàlisi de l'acció educativa del museu vindrà determinada per l'estudi dels materials didàctics, per l'adequació dels conceptes didàctics, però també per l'eficàcia comunicativa i la projecció d'aquests, així com per l'adequació d'espais i continguts. I per a tot açò es tindrà en compte alguns elements estructurals bàsics: establiment d'objectius o finalitats educatives; selecció i organització de continguts; determinació de les activitats; especificació dels recursos necessaris i disponibles; previsió de mecanismes i instruments d'avaluació.

La utilització de les xarxes socials que proporcionen un canal multidireccional de comunicació serà base de recollida de part de les informacions. En aquest sentit el museu ofereix un recorregut informatiu i visual mitjançant la seua pàgina web. Aquesta connexió virtual prèvia prepara al destinatari per a la posterior experiència i pot introduir factors com la connectivitat o la interacció, integrant l'experiència presencial amb l'ús de les noves tecnologies (Huerta, 2011, p. 57). Davant d'una demanda real de consum cultural, el museu pot presentar el seu patrimoni amb unes estratègies comunicatives comprensives i motivadores a través de les xarxes socials, el que pot resultar beneficiós no sols per als destinataris, sinó també per a la pròpia entitat. D'eixa forma podrem obtenir algunes opinions i elements mesurables com: quin impacte tenen els materials patrimonials de l'exposició sobre els destinataris; si s'aconsegueix la comunicació entre el destinatari i el museu com a espai d'interacció, tant física (manipulació), emocional (empàtica) o intel.lectual (conceptualitzacions); quin impacte té la forma en què es presenta l'exposició (il.luminació, panells, imatges, recursos tecnològics); quin impacte tenen els recursos i activitats didàctiques en els processos d'aprenentatge dissenyats cap a un destinatari escolar, etc.

A la conservació dels materials i testimonis culturals s'uneix la consecució d'elements educatius que permeten el seu gaudi per part dels destinataris en general, a la vegada que es tracta la sensibilització per a la preservació i transmissió a les generacions futures, incidint també en certs dissenys que no resulten aliens a l'educació formal o escolar. En definitiva es tracta de mostrar, d'acord al museu que ara presentem, la seua concepció del patrimoni, la consonància d'allò exposat amb les competències curriculars corresponents a cada etapa educativa, la sensibilització de la societat per la seua herència històrica i l'educació en valors relativa al patrimoni. I tot això queda, en l'actualitat, inserit en l'àmbit de les noves tecnologies i en la seua projecció digital (Ibáñez et alii, 2018). Però a més a més, les possibilitats que ofereix Internet permeten enriquir el discurs museístic tant com interessi a cada persona, de tal manera que la visita a l'exposició o al museu poden ser l'element d'inserció en un camí d'aprenentatge, però no necessàriament han de ser el punt final. Això ens mostra que el museu pot ser una entitat viva que canvia i es renova constantment atenent a les noves necessitats i també als nous elements de comunicació (Besolí, 2001-02).

\section{Conclusions}

No es tracta solament d'avaluar el que s'ha fet al museu, on algunes de les seues exposicions han sorgit d'investigacions concretes provinents de l'Arxiu del Col-legi de l'Art Major de la Seda de València, establert dins del propi museu i amb sala expositiva pròpia com hem mencionat. Es tracta també de veure les potencialitats didàctiques futures que 
poden projectar-se des del propi museu i des de l'arxiu relatives a noves accions educatives i expositives, aspectes aquests últims en els quals troba sentit el treball de Navarro i Huerta (2019) sobre els museus de la seda; o aquells altres que estem desenvolupant en I'actualitat sobre edició de fonts (Navarro i Aparici, 2020); o la ponència conjunta acceptada en la propera Settimana di Studi di Prato sobre la moda com a motor econòmic (Navarro i Aparici, en premsa); o també el treball conjunt sobre la producció de seda i la relació fiscal amb la Generalitat Valenciana al llarg de l'Edat Mitjana (Navarro i Aparici, 2019). Tots aquests treballs, vinculats a l'edició de fonts i documents relatius a l'àmbit que envolta el món de la seda resulten importants per a valorar la seua posterior projecció didàctica d'acord als valors educatius que pretén mostrar el propi museu, atenent als diferents nivells competencials dels destinataris, és a dir, passar de la mera metodologia expositiva a un plantejament acord a les necessitats dels visitants que permeta un aprenentatge significatiu, oferint la possibilitat de creació de nous tallers i manipulació directa de determinats útils, estris o documents (experimental i lúdic); quaderns de camp i investigació (segons edats i tenint en compte possibles adaptacions inclusives); guies específiques personalitzades per a determinats tipus d'usuari; i en relació a la difusió d'aquestes activitats educatives del museu, utilització de les xarxes socials que proporcionen un canal multidireccional de comunicació. Amb tot això s'afavorirà un ensenyament-aprenentatge de la història en un context no formal ni reglat però molt vinculat al seu torn a l'àmbit escolar, que permeta diversos ritmes i temps d'aproximació a la mateixa, que estimule la participació activa, la imaginació i creativitat, les capacitats d'observació i abstracció, el plantejament d'interrogants, la necessitat de descobrir més, la capacitat lúdica i el gaudi en l'aprenentatge, etc. aspectes tots dissenyats i implementats segons els valors educatius del respecte i la conservació del patrimoni. 


\section{Referències}

Álvarez, C; García, M. (2011) «Museos pedagógicos: ¿museos didácticos?».Didáctica de las Ciencias Experimentales y Sociales, núm. 25, p. 103-116.

Asensio, M; Pol, E. (2003) «Aprender en el museo». Íber: Didáctica de las Ciencias Sociales, Geografía e Historia, núm. 36, p. 62-67.

Aso, B.; García-Ceballos, S.; Rivero, P.; Fontal, O. (2016) «Estudio de caso de la acción educativa del Museu Afro Brasil de São Paulo». Clio. History and History teaching, núm. 42. Enllaç: http://clio.rediris.es.

Besolí, A. (2001-02). «L'ús de les tecnologies audiovisuals com a recurs didàctic en museus d'història i espais de presentació del patrimoni». Temps d'Educació, núm. 26, p. 99115.

Calaf, R. (2009) Didáctica del patrimonio: epistemología, metodología y estudio de casos. Gijón, Trea.

Escribano, A.; Serrano, F. J.; Miralles, P. (2019) «Diseño y validación de un cuestionario para el estudio de la relación y colaboración museo y escuela (MUSELA DOC)». Revista Electrónica Interuniversitaria de Formación del Profesorado, núm. 22 (1), p. 103-119. Enllaç: http://dx.doi.org/10.6018/reifop.22.1356991

Fernández, M. (2003) «Los museos: espacios de cultura, espacios de aprendizaje». Íber: Didáctica de las Ciencias Sociales, Geografía e Historia, núm. 36, p. 55-61.

González, T. (2008) «El museu, espai de trobada entre l'educació i la cultura». Temps d'Educació, núm. 35, p. 119-126.

Huerta, R. (2011) «Maestros, museos y artes visuales. Construyendo un imaginario educativo». Arte, Individuo y Sociedad, núm. 23/1, p. 55-72.

Ibáñez, A; Fontal, O; Rivero, P. (2018) «Educación patrimonial y TIC en España: marco normativo, variables estructurales y programas referentes». Arbor Ciencia, $\begin{array}{llllll}\text { Pensamiento } y & \text { Cultura, núm. } & 194 & \text { (788): } & \text { a448. }\end{array}$ http://doi.org/10.3989/arbor.2018.788n2008.

Liceras, V. (2018) «Contenido museográfico del Colegio del Arte Mayor de la Seda de València», a WAA, Rehabilitación arquitectónica del Colegio del Arte Mayor de la Seda de Valencia. La recuperación de un símbolo del esplendor de Valencia. València, Laimprenta CG, p. 175-198.

Navarro, G. (1999) Los orígenes de la sedería valenciana (siglos XV-XVI). València. Ajuntament de València.

Navarro, G. (2013) «Las rutas de la seda como itinerarios culturales. Exposiciones y museología», a R. Huerta; R. de la Calle (Eds.) Patrimonios migrantes. València, Publicacions de la Universitat de València, p. 49-58.

Navarro, G. (2018) «Presentación», a VVAA, Rehabilitación arquitectónica del Colegio del Arte Mayor de la Seda de Valencia. La recuperación de un símbolo del esplendor de Valencia. València, Laimprenta CG, p. 13-14.

Navarro, G; Aparici, J. (2019) «El manifest de la seda i la Generalitat Valenciana». La Veu del Regne. Representació política, recursos públics i construcció de l'estat. 600 anys de la Generalitat Valenciana. Congrés Internacional, València, octubre 2018.

Navarro, G; Aparici, J. (en premsa) «El color de las sedas valencianas en el mercado europeo (1475-1513)». Settimana di Studi di Prato (maig 2021). Istituto di Storia Economica Francesco di Marco Datini. 
Navarro, G; Aparici, J. (en premsa, 2020) El Manifest de les Sedes del Tall del Drap de València (1475 i 1512-1513). Fonts històriques Valencianes, Universitat de València.

Navarro, G.; Huerta, R. (Coord.) (2019) Museos de la Seda / Silk Museums, València.

Rivero, P.; Fontal, O.; Martínez, M.; García, S. (2018) «La educación patrimonial y el patrimonio arqueológico para la enseñanza de la historia: el caso de Bílbilis». Ensayos. Revista de la Facultad de Educación de Albacete, núm. 33/1, p. 23-37. Enllaç: http://www.revista.uclm.es/index.php/ensayos

Serrat, N. (2008) «Accions didàctiques en el marc dels museus. Una investigació entre el museu i l'escola». Temps d'Educació, 34, p. 167-182.

Suárez, M. A.; Gutiérrez, S.; Calaf, R.; San Fabián, J.L. (2013) «La evaluación de la acción educativa museal: una herramienta para el análisis cualitativo». Clío 39, p. 1-45, Enllaç: http://clio.rediris.es.

Suárez, M. A.; Calaf, R.; San Fabián, J.L. (2014) «Aprender historia a través del patrimonio. Los casos del Museo del Ferrocarril de Asturias y del Museo de la Inmigración de Cataluña». Revista de Educación, núm. 365, p. 38-66. 


\section{El Museo de la Seda de València: acciones educativas}

Resumen: El Museo de la Seda de València presenta una serie de puntos fuertes para desarrollar acciones educativas y facilitar su posterior proyección digital en relación al patrimonio histórico (el propio edificio, las exposiciones permanentes y las itinerantes, o el archivo gremial). Proponemos el análisis de sus posibilidades didácticas y los materiales oportunos; la identificación del uso real que de ello se deriva (a través de encuestas y redes sociales) y así observar su capacidad empática con el destinatario para adecuar, de forma progresiva y si fuera necesario, la oferta didáctica y cultural.

Palabras clave: Patrimonio, educación, didáctica, museo, seda.

\section{Le Musée de la soie de Valence: actions éducatives}

Résumé: Le Musée de la soie de Valence, en Espagne, présente une série de points forts pour développer des actions éducatives et faciliter sa projection numérique postérieure en rapport avec le patrimoine historique (l'édifice en soi, les expositions permanentes et itinérantes, ou les archives des musées). Dans cet article, nous proposons l'analyse de ses possibilités didactiques et des matériaux adéquats, ainsi que l'identification de l'usage réel qui en dérive (au moyen d'enquêtes et de réseaux sociaux) pour pouvoir observer sa capacité à établir une relation empathique avec le destinataire afin d'adapter, de manière progressive et en cas de nécessité, l'offre didactique et culturelle.

Mots clés: Patrimoine, éducation, didactique, musée, soie.

\section{The Valencia Silk Museum: educational activities}

Abstract: The holdings of the Valencia Silk Museum can be used to carry out educational activities and to promote the digital impact of its historical heritage, including the building itself, the permanent and travelling exhibitions, and the guild archive. We propose an analysis of its teaching proposals and materials; an assessment of their real use (by means of a survey and the social networks) and of the museum's ability to connect with its target audience, if necessary by progressively adapting its teaching and cultural offer.

Keywords: Heritage, education, didactics, museum, silk. 